\author{
ANNA SOBCZAK \\ Uniwersytet im. Adama Mickiewicza \\ $w$ Poznaniu
}

\title{
MCJOB \\ - MIĘDZY DEHUMANIZACJĄ PRACY \\ A WSTĘPEM DO KARIERY ZAWODOWEJ
}

\begin{abstract}
AвSTRACT. Sobczak Anna, Mcjob - między dehumanizacja pracy a wstępem do kariery zawodowej [McJob - Between Dehumanization of Work and the Introduction to a Professional Career]. Studia Edukacyjne nr 47, 2018, Poznań 2018, pp. 245-256. Adam Mickiewicz University Press. ISSN 1233-6688. DOI: $10.14746 /$ se.2018.47.16
\end{abstract}

The service sector plays an increasingly important role in modern society, called a consumer society. Nowadays we want to get everything easily and quickly. That is why the fast-food industry, specially McDonald's company become more and more popular. Work in fast-food restaurants (but not only there) is called a McJob. The term is commonly defined as a low-paid, unskilled, entry-level job with few prospects, one that requires zero creative or intellectual involvement. McJobs are usually filled by young people. This article tries to answer the question whether employment of this type means dehumanization of work or whether it can be an introduction to a professional career.

Key words: McJob, dehumanization of work, professional career, young people

Permanentne zmiany zachodzące na rynku pracy, wyłanianie się nowych form zatrudnienia, zawodów, sposobów świadczenia pracy, a także nowych relacji pomiędzy wykształceniem symbolizowanym przez dyplom akademicki a zatrudnieniem przyczyniły się do powstawania kolejnych koncepcji, których autorzy podejmowali próbę wyjaśniania występujących tendencji i zjawisk w tym zakresie. Od lat 60. XX wieku dominowała teoria kapitału ludzkiego, której zwolennicy zakładają, że związek pomiędzy osiągnięciami edukacyjnymi a statusem zawodowym odznacza się racjonalnością - a więc im wyższe szczeble edukacji zdołają przejść jednostki, tym uzyskają większe szanse na osiągnięcie sukcesu oraz zdobycie atrakcyjniejszej, ciekawszej, le- 
piej płatnej pracy, a przy tym następuje rozwój całych społeczeństw ${ }^{1}$. Praca ta należałaby, zgodnie z koncepcją dualnego rynku pracy, do segmentu pierwotnego. Bowiem, segment ten, według przywołanej teorii rynku pracy, charakteryzuje się zatrudnieniem stabilnym, dobrze płatnym, z perspektywami rozwoju oraz awansu zawodowego, a także wymagającym wysokich kompetencji oraz kwalifikacji².

Obecnie prosta zależność pomiędzy osiągnięciami edukacyjnymi a pozycją społeczno-zawodową, a więc i charakterem wykonywanej pracy nie istnieje. Coraz częściej wysoko wykształcone osoby, czy to z własnego wyboru czy z konieczności (w większości przypadków), podejmują pracę rutynową, na najniższych szczeblach, niewymagającą odpowiedniego dyplomu. Sytuacja, kiedy osoby z wyższym wykształceniem zmuszone są do podjęcia pracy poniżej ich kwalifikacji niewątpliwie związana jest $\mathrm{z}$ występującym obecnie przeedukowaniem społeczeństwa oraz inflacją dyplomu akademickiego ${ }^{3}$. Współcześnie obserwujemy zjawisko, w którym część osób, także legitymujących się wykształceniem wyższym, wykonuje pracę określaną jako McJob, czyli pracę nisko płatną, mało prestiżową, niewymagającą wysokich kwalifikacji oraz pozbawioną przyszłości ${ }^{4}$. W niniejszym artykule podejmę próbę zrekonstruowania koncepcji makdonaldyzacji pracy, stanowiącej jedną z najbardziej kontrowersyjnych koncepcji odnoszących się do charakteru i sposobu wykonywania pracy przez pewną część współczesnego społeczeństwa.

Mimo że termin McJob został użyty po raz pierwszy przez socjologa Amitaia Etzioniego w roku $1986^{5}$, to spopularyzował je kilka lat później Douglas Coupland, który w swojej książce dotyczącej ówczesnego pokolenia młodych, czyli generacji X, przypisał zatrudnienie w charakterze McJob ${ }^{6}$. Natomiast, w roku 1993 pojęcie to zostało szerzej zdefiniowane przez George'a Ritzera, który wpisał je w swoją koncepcję makdonaldyzacji społeczeństwa, uwzględniającą również rynek pracy $^{7}$. Zanim przybliżę pojęcie McJob, przedstawię istotę oraz główne założenia makdonaldyzacji społeczeństwa.

${ }^{1}$ Ch.J. Hurn, The limits and possibilities of schooling. An introduction to the sociology of education, Boston 1985, s. 35-36, podaję za: Z. Melosik, Kultura popularna i tożsamość młodzieży. W niewoli władzy i wolności, Kraków 2013, s. 322.

${ }^{2}$ M. Reich, D.M. Gordon, R.C. Edwards, Dual labor markets. A theory of labor market segmentation, American Economic Review, 1973, 63(2), s. 359-365.

${ }^{3}$ Z. Melosik, Uniwersytet $i$ społeczeństwo. Dyskursy wolności, wiedzy i władzy, Kraków 2009, s. 135.

${ }^{4}$ D. Coupland, Generation X. Tales for an accelerated culture, New York 1991, s. 5.

${ }_{5}$ A. Etzioni, The fast-food factories. McJobs are bad for kids, https://www.washingtonpost. com/archive/opinions/1986/08/24/the-fast-food-factories-mcjobs-are-bad-for-kids/b3d7bbeb-5e9a-4335-afdd-2030cb7bc775/?utm_term=.da787f27c4f0 [dostęp: 18.03.2018].

${ }^{6}$ D. Coupland, Generation X.

7 G. Ritzer, Makdonaldyzacja społeczeństwa, Warszawa 2003. 
Proces makdonaldyzacji powiązany jest z wieloma współczesnymi zjawiskami społecznymi, do których niewątpliwie zaliczyć należy postępującą globalizację i nieustającą konsumpcję nia ze społeczeństwem konsumpcji oraz „społeczeństwem spektaklu”. Guy Debord określa ten spektakl jako „etap całkowitego podporządkowania towarom całości życia społecznego" i dodaje, że „na tym etapie konsumpcja jest już, obok produkcji, dodatkowym obowiązkiem mas" ${ }^{\prime 9}$. Dla współczesnego społeczeństwa konsumpcja stanowi cel sam w sobie, a więc jest czymś samonapędzającym się. Jak zauważa Zygmunt Bauman, „społeczeństwo konsumentów głosi niemożność zaspokojenia i mierzy jego postępy stale rosnącym popytem". W konsumeryzmie nie chodzi zatem o zaspokajanie potrzeb, lecz ciągłe tworzenie nowych form konsumpcji ${ }^{10}$.

Ten stale rosnący popyt oraz niezaspokojone pragnienia społeczeństwa konsumpcyjnego były jedną z pobudek dynamicznego rozwoju instytucji oferujących towary i usługi, w szczególności placówek typu fast food, które wychodziłyby naprzeciw oczekiwaniom współczesnych konsumentów charakteryzujących się "szybkim stylem życia”. Jak wskazuje Zbyszko Melosik, restauracje Mcdonald's zdają się być najbardziej spektakularnym przykładem organizacji wpisujących się zarówno w kulturę fast food, jak i w kulturę instant, której fundamentalną dewizą jest orientacja na natychmiastowość ${ }^{11}$. To właśnie zasady funkcjonowania placówek Mcdonald’s posłużyły George'owi Ritzerowi do wyjaśnienia zachodzących procesów oraz zjawisk społecznych, które określił, jak już wcześniej wspomniano, mianem makdonaldyzacji społeczeństwa ${ }^{12}$, gdyż zdaniem przywołanego autora: „tam, gdzie konsumujemy towary i usługi, zachodzą rewolucyjne zmiany, które mają głęboki wpływ nie tylko na charakter konsumpcji, lecz także na życie społeczne"13.

Makdonaldyzacja więc, zdaniem George'a Ritzera, oddziałuje zarówno na branżę masowego żywienia, jak i sferę pracy, edukacji, opieki zdrowotnej, podróży, wypoczynku, żywienia dietetycznego, na relacje rodzinne oraz zasadniczo na wszelkie aspekty życia społecznego ${ }^{14}$. Pierwszym celem mojego tekstu, jak już nadmieniono, jest analiza tej kategorii, jaką jest McJob na tle procesów makdonaldyzacji społeczeństwa. Podejmę jednak również próbę odpowiedzi na zasadnicze pytanie: czy zatrudnienie tego typu sprowadza się do dehumanizacji pracy, czy też może stanowić fundament dla rozwoju zawodowego i należy postrzegać ją w kategoriach pracy dla ambitnych? Oto

\footnotetext{
8 Tamże, s. 284-291.

9 G. Debord, Społeczeństwo spektaklu oraz rozważania o społeczeństwie, Warszawa 2006, s. 48.

10 Z. Bauman, Consuming life, Journal of Consumer Culture, 2001, 1(1), s. 13.

11 Z. Melosik, Kultura popularna i tożsamość młodzieży, s. 186.

${ }^{12}$ G. Ritzer, Makdonaldyzacja społeczeństwa, s. 10.

${ }^{13}$ G. Ritzer, Magiczny świat konsumpcji, Warszawa 2001, s. 8.

${ }^{14}$ G. Ritzer, Makdonaldyzacja społeczeństwa, s. 15.
} 
bowiem, termin McJob jest zazwyczaj używany dla opisu pracy, która jest nudna, powtarzalna, niewymagająca wysokich kwalifikacji, a przede wszystkim nisko płatna oraz z nikłymi perspektywami na rozwój ${ }^{15}$. Jednakże, jak zauważa Cora Daniels, pomimo powszechnej krytyki zatrudnienia w branży fast food, niektórzy dostrzegają w tego typu pracy możliwości rozwoju kompetencji i potencjalne miejsce na rozpoczęcie oraz rozwijanie kariery zawodowej $^{16}$. George Ritzer zauważa, że McDonald's przemawia do ludzi na wiele różnych sposobów, między innymi próbuje przekonać społeczeństwo, że pracownicy restauracji to "ludzie młodzi i energiczni, a kadra kierownicza łagodna i troskliwa"17. Warty podkreślenia jest fakt, że firma McDonald's w roku 2013 zatrudniała w swoich restauracjach aż 1,7 miliona pracowników na całym świecie ${ }^{18}$.

Należy zatem w tym miejscu przytoczyć główne założenia i mechanizmy makdonaldyzacji współczesnego społeczeństwa według George’a Ritzera, który podkreśla, że jedzenie szybkich dań w McDonald's stało się symbolem społeczno-kulturowym, również symbolem nowego stylu życia. Restauracja ta odniosła sukces, ponieważ zapewnia pracownikom, menedżerom oraz konsumentom sprawność działania, wymierność, przewidywalność i możliwość sterowania, które stanowią cztery aspekty zjawiska makdonaldyzacji społeczeństwa ${ }^{19}$, a jak podkreśla Barry Smart, za najważniejszy jego przejaw George Ritzer uznał procesy racjonalizacji we współczesnym świecie ${ }^{20}$.

Sprawność definiowana jako optymalny sposób docierania z punktu do punktu jest ważnym elementem sukcesu McDonald's. Konsumentom oferuje się najlepszą i najszybszą drogę zaspokajania głodu ${ }^{21}$. Wzorzec baru typu fast food gwarantuje, lub przynajmniej stwarza, pozory sprawnego zaspokajania innych potrzeb. Trzeba dodać, że instytucje działające według modelu McDonald's zapewniają podobnie sprawne odchudzanie się, dopasowywanie nowych okularów, dokonywanie przeglądu samochodu lub wypełnienie formularza zeznań podatkowych. Tak samo jak ich klienci, w instytucjach zmakdonaldyzowanych sprawnie działają również pracownicy wykonujący kolejne etapy z góry zaplanowanego procesu, co stanowi cechę charakterystyczną

15 A.M. Gould, Working at McDonalds: some redeeming features of McJobs, Work, Employment and Society, 2010, 24(4), s. 780-781.

16 C. Daniels, 50 Best companies for minorities, Fortune, 2004, 149(13), s. 137, podaję za: A.M. Gould, Working at McDonalds, s. 781.

17 G. Ritzer, Makdonaldyzacja społeczeństwa, s. 24.

18 http://www.mcdonalds.co.uk/ukhome/whatmakesmcdonalds/questions/work-with-us/jobs/how-many-people-are-employed-by-mcdonalds-in-the-uk-and-worldwide.html [dostęp: 26.03.2018].

19 G. Ritzer, Makdonaldyzacja społeczeństwa, s. 30.

20 B. Smart, Resisting McDonaldization. Theory, process and critique, [w:] Resisting McDonaldization, red. B. Smart, London 1999, s. 2-3.

${ }^{21}$ G. Ritzer, Magiczny świat konsumpcji, s. 144-145. 
zatrudnienia określanego jako McJob. Uczeni są tego przez swoich menedżerów, którzy pilnie obserwują, czy ich podwładni wykonują swoje zadania jak należy. Wysokiemu poziomowi sprawności pracy sprzyjają także zasady oraz przepisy organizacyjne. Sprawność oznacza więc wybór optymalnych środków do celu i dlatego jest tym aspektem makdonaldyzacji, który najczęściej bywa utożsamiany z obserwowalnym przyspieszeniem tempa życia ${ }^{22}$.

Innym elementem makdonaldyzacji jest wymierność. Polega ona na nadawaniu szczególnego znaczenia ilościowym cechom sprzedawanych produktów (ceny, wielkości porcji) oraz świadczonych usług (czasu oczekiwania na produkt). W organizacjach zmakdonaldyzowanych jakość została zastąpiona ilością, dostarczenie danej rzeczy lub usługi w dużej ilości lub szybko zakłada, że musi być ona „dobra”. Podkreśla się, że pracownicy zatrudnieni w systemach zmakdonaldyzowanych także mają skłonność do przywiązywania szczególnej uwagi do kwestii ilościowych, a nie jakościowych aspektów swojej pracy. Skupiają się w szczególności na szybkości wykonywania zadań, gdyż dopuszcza się jedynie niewielkie różnice jakości pracy. Od pracownika wymaga się dużo szybkiej pracy za małe wynagrodzenie. Jednocześnie krytycy stwierdzają, że dla pracowników zatrudnionych w ramach McJob wymierność to najczęściej niewielka satysfakcja lub brak satysfakcji z wykonywanych zadań, na czym cierpi zarówno praca, jak i towary oraz usługi ${ }^{23}$.

Kolejnym aspektem makdonaldyzacji jest przewidywalność. Odnosi się ona do gwarancji, że McDonald's oferuje swoim klientom takie same wyroby oraz usługi, zawsze i wszędzie. Świadomość, że restauracje McDonald's zapewniają pewność swojego serwisu doskonale wpływa na samopoczucie klientów. W świecie zmakdonaldyzowanym przewidywalne jest także postępowanie pracowników. Swoje obowiązki wypełniają zgodnie z regułami działania firmy i poleceniami przełożonych. W wielu przypadkach łatwo można przewidzieć, jak pracownicy się zachowają lub nawet, co powiedzą ${ }^{24}$. Jak wskazuje Robin Leidner, pracownicy wykorzystują gotowe scenariusze rozmów z klientami, co doprowadza do tego, że każdy klient traktowany jest tak samo, a relacje pomiędzy pracownikami a klientami są $\mathrm{w}$ znacznym stopniu przewidywalne ${ }^{25}$. W przypadku pracownika wykonującego McJob zasada przewidywalności odnosi się do charakteru wykonywanej przez niego pracy, która zwykle jest nieskomplikowana i nie wymaga wielu umiejętności. Niektórzy pracownicy preferują lekką, powtarzalną oraz niewymagającą pracę, podczas wykonywania której są w stanie myśleć o czymś zupełnie innym

${ }^{22}$ G. Ritzer, Makdonaldyzacja społeczeństwa, s. 30-78.

23 Tamże, s. 31-114.

${ }^{24}$ Tamże, s. 32.

${ }^{25}$ R. Leidner, Fast food, fast talk. Service work and the routinization of everyday life, Berkley 1993, s. 29. 
lub oddawać się marzeniom ${ }^{26}$. Jednakże, przewidywalność ma też znaczną wadę - odznacza się tendencją do zamieniania wszystkiego - pracy, zarządzania, konsumpcji - w intelektualnie odrętwiającą rutynę ${ }^{27}$.

Ostatnim elementem zjawiska makdonaldyzacji jest sterowanie, któremu są poddawane osoby wkraczające w świat McDonald'sa. Klienci zachowują się zgodnie z oczekiwaniami menedżerów, czyli szybko jedzą i wychodzą, a dzieje się to za sprawą przemyślanych działań restauracji, zmierzających do pojawienia się w placówkach kolejek, ubogiego jadłospisu oraz niewygodnych krzeseł. Natomiast, poprzez sprzedaż przez okienka dla podjeżdżających samochodami, klienci odjeżdżają, zanim zjedzą. W systemach zmakdonaldyzowanych silnemu sterowaniu ulegają również ludzie, którzy są w nich zatrudnieni na stanowiskach pracy określanych jako McJob. W ich przypadku sterowanie odbywa się w bardziej otwarty oraz bezpośredni sposób niż w odniesieniu do klientów. Pracownicy są szkoleni w dokładnym wykonywaniu niedużej liczby czynności. Siła procesu sterowania jest większa za sprawą określonych rozwiązań organizacyjnych oraz technicznych. Menedżerowie oraz kontrolerzy dbają, aby pracownicy postępowali ściśle według obowiązujących zasad i procedur. Część pracy wykonywana jest, jak określił to George Ritzer "zdehumanizowanymi środkami technicznymi”, a im więcej zrobią te środki techniczne, nim jedzenie znajdzie się $w$ restauracji, tym pracownicy mają zarówno mniej zadań, jak i sposobności do wykorzystania swoich umiejętności oraz własnego osądu ${ }^{28}$.

W ostatnich latach proces makdonaldyzacji, a więc i wzrost zatrudnienia w charakterze McJob, nabrał dużego tempa, gdyż z pozoru to szkodliwe zjawisko wywołuje także zmiany pozytywne, do jakich należy zaliczyć między innymi pojawienie się ekonomicznych towarów oraz usług, które są obecnie szeroko dostępne, ujednolicenie jakości produktów i usług, co spowodowało, że przynajmniej część ludzi otrzymuje dzisiaj lepsze towary oraz korzysta z lepszych usług, niż miało to miejsce przed makdonaldyzacją czy też możliwość dostania pożądanych dóbr niemal natychmiast oraz w sposób o wiele wygodniejszy niż kiedyś. Jednak z drugiej strony, w przedmiocie literatury istnieje widoczna krytyka makdonaldyzacji społeczeństwa. Krytycy twierdzą, że organizacje zmakdonaldyzowane to miejsca, gdzie ludzie są odczłowieczani, gdzie nie zawsze mogą być „w pełni” ludźmi, gdyż muszą dostosować się do panujących zasad oraz reguł wynikających z procesów racjonalnego postępowania $^{29}$. Ta negatywna opinia w dużej mierze odnosi się do charakteru i wa-

${ }^{26}$ W. Baldamus, Tedium and traction in industrail work, [w:] Men and work in modern Britain, red. D. Weir, London 1973, s. 78-84, podaję za: G. Ritzer, Makdonaldyzacja społeczeństwa, s. 149-150.

27 G. Ritzer, Makdonaldyzacja społeczeństwa, s. 150.

28 Tamże, s. 34-185.

29 Tamże, s. 36-40. 
runków wykonywanej pracy w organizacjach zmakdonaldyzowanych. Przeciwnicy McJob postrzegają tego typu zatrudnienie jako dehumanizację pracy ${ }^{30}$. System organizacji pracy w restauracjach McDonald's przyrównać można do działania taśmy montażowej, przy której znajdują się zarówno klienci czekający w kolejce po hamburgera, jak i pracownicy przygotowujący w pośpiechu oraz w sposób zmechanizowany, rutynowy jedzenie ${ }^{31}$. Dehumanizacja będąca cechą systemów zmakdonaldyzowanych stanowi główny zarzut dla tego typu organizacji, gdyż zdaniem jej przeciwników odbierają one pracującym w nich ludziom sposobności na kreatywność i wykorzystywanie swojego potencjału.

Należy w tym miejscu podkreślić, że McJob nie występuje jedynie w barach szybkiej obsługi. Linda Ann Treiber zauważa, że postępujący proces makdonaldyzacji społeczeństwa prowadzi do tworzenia się coraz większej liczby stanowisk pracy wpisujących się w specyfikę McJob, czyli pracy obejmującej wąski zakres zadań, która pozbawia pracowników twórczości ${ }^{32}$. Sektor usług, zwłaszcza stanowiska znajdujące się na niższych szczeblach zawodowej hierarchii, produkuje ogromną liczbę miejsc pracy, z których większość wymaga nikłych bądź nie wymaga żadnych umiejętności. Nie ma tutaj lepszego przykładu niż zatrudnieni w przemyśle fast food, w którym znaczna część pracowników to ludzie młodzi ${ }^{33}$. Również George Ritzer wskazuje, że „nowa zawodowa kreacja" nie stanowi jedynie domeny pracy w restauracji McDonald czy innych firm specjalizujących się w serwowaniu szybkich dań. Wiele innych stanowisk pracy na niskich szczeblach zostało także zmakdonaldyzowanych. Jednak jeszcze bardziej uderzający jest fakt, że obecnie duża liczba miejsc pracy średniego szczebla jest również przekształcana w McJobs, co dzieje się za sprawą procesu jej zmechanizowania, uproszczenia oraz zrutynizowania, a w konsekwencji od ludzi ją wykonujących nie oczekuje się wysokich umiejętności oraz kreatywności ${ }^{34}$. Dlatego, zasady organizacji oraz wypełniania zawodowych obowiązków w ramach McJob przeczą ogólnej definicji humanizacji pracy. Salomea Kowalewska podkreśla, że proces humanizacji warunków pracy „jest wyrazem przekonania, iż można tak zorganizować warunki pracy, aby dawała ona ludziom zadowolenie i była czynnikiem ich rozwoju", a jest to możliwe jedynie poprzez usuwanie wszelkich przeszkód, które stoją na drodze do przekształcenia pracy w działalność twórczą oraz rozwijającą

${ }^{30}$ G. Ritzer, McJob. McDonalidization and the workplace, [w:] Seeing ourselves. Classic, contemporary, and cross-cultural readings in sociology, red. J.J. Macionis, N.V. Benokraitis, New Jersey 2001, s. 139.

31 G. Ritzer, Makdonaldyzacja społeczeństwa, s. 38-39.

32 L.A. Treiber, Mcjobs and pieces of flair: Linking McDonaldization to alienating work, Teaching Sociology, 2013, 41(4), s. 370.

33 C. Allan, G.J. Bamber, N. Timo, Fast-food work: are McJobs satisfying? Employee Relations, 2006, 28(5), s. 403.

34 G. Ritzer, McJob. McDonalidization, s. 139. 
człowieka $^{35}$. Tymczasem, w organizacjach zmakdonaldyzowanych dąży się do coraz większej racjonalizacji pracy wykorzystując do tego zmechanizowane środki produkcji, a także ściśle określone reguły oraz procedury, zgodnie z którymi powinni postępować pracownicy, aby ich praca była sprawna, wymierna, przewidywalna, a także kontrolowalna. Podczas dążenia do opisanej formy wykonywania pracy zapomina się o aspekcie ludzkim i potrzebach jednostki, dla której praca $w$ wielu przypadkach nie stanowi jedynie środka do uzyskania dochodu, lecz jak to określa Małgorzata Sikorska „stanowi także punkt skupienia wszystkich elementów, z których budowana jest jej tożsamość" oraz poczucie własnej wartości i samorealizacji ${ }^{36}$.

Wspomniane poczucie samorealizacji oraz własnej wartości niezwykle trudno budować ludziom młodym, którzy jak to zostało przytoczone wcześniej, są głównymi adresatami oraz „wykonawcami” McJob i którym w myśl zasad neoliberalnego społeczeństwa wpaja się przekonanie, że wspomniany sukces zależy wyłącznie od nich samych, a jego miarą są osiągnięcia ekonomiczno-finansowe, do których powinni dążyćcin. Dlatego współcześnie w wielu przypadkach McJob nie tylko nie spełnia oczekiwań wielu młodych, ale stanowi też źródło poczucia porażki, szczególnie kiedy dana osoba nie ma przed sobą, z różnych przyczyn, innych, lepszych perspektyw zawodowych. Ponadto, wyższe ambicje młodych, z których większość może obecnie „pochwalić” się dyplomem szkoły wyższej, niż zmakdonaldyzowana praca wynikają, zgodnie z teorią Earla Hoppera mówiącej o regulowaniu aspiracji jednostek, z procesów ich „podgrzewania” przez system edukacji. Według wspomnianej koncepcji, w cyklu kształcenia następuje selekcja uczniów poprzez „wychładzanie” aspiracji tych, którzy są mniej uzdolnieni oraz „podgrzewanie" aspiracji tych o większych zdolnościach, a następnie zachęca się ich do kontynuowania nauki na wyższych szczeblach edukacji, w przeciwieństwie do pierwszej grupy, która jest posyłana na rynek pracy. Współcześnie znaczna część młodych kontynuuje naukę na najwyższym szczeblu sytemu edukacji, czyli studiach wyższych, gdzie ich aspiracje, zgodnie z teorią Earla Hoppera, są w dużym stopniu „podgrzewane”, a jak stwierdza wspomniany autor, „z im większym powodzeniem działa system edukacyjny podczas «podgrzewania» aspiracji na danym etapie, tym trudniejsze będzie «wychłodzenie» osób o rozbudzonych aspiracjach" ${ }^{\prime 38}$. Nie ulega wątpliwości, że osoby

${ }^{35}$ S. Kowalewska, Humanizacja pracy, Warszawa 1971, s. 5-39.

${ }^{36}$ M. Sikorska, Zmiany postaw Polaków wobec pracy, [w:] Polacy wśród Europejczyków. Wartości społeczeństwa polskiego na tle innych krajów europejskich, red. A. Jasińska-Kania, M. Marody, Warszawa 2002, s. 39.

37 A. Gromkowska-Melosik, Edukacja i nierówność społeczna kobiet. Studium dynamiki dostępu, Kraków 2011, s. 146.

${ }^{38}$ E. Hopper, Educational systems and selected consequences of patterns of mobility and non-mobility in industrial societies: A theoretical discussion, [w:] Readings in the theory of educational systems, 
z tytułem magistra zmuszone do pracy w McDonald's są w maksymalnym stopniu „wychłodzone”, co musi wzbudzać ich frustrację.

Obecnie, jak to zostało już zaakcentowane wcześniej, mamy do czynienia ze zjawiskiem nadpodaży absolwentów szkół wyższych w społeczeństwie, co doprowadziło do sytuacji, w której nie ma korelacji pomiędzy istniejącą strukturą zawodową i potrzebami rynku a strukturą absolwentów opuszczających placówki edukacji wyższej ${ }^{39}$. W konsekwencji przeedukowania społeczeństwa oraz niedopasowania strukturalnego na rynku pracy, część młodych legitymujących się dyplomem szkoły wyższej zmuszona jest podejmować zatrudnienie niewymagające odpowiednich kompetencji oraz kwalifikacji, często niskopłatne oraz bez perspektyw na rozwój ${ }^{40}$, które zalicza się zatem do McJobs. To właśnie najczęściej osoby wysoko wykształcone, w większości przypadkach, o znacznie wyższych aspiracjach zawodowych oraz oczekiwaniach odnośnie warunków pracy traktują McJobs jako przykrą konieczność i jedynie drobny „epizod” w swojej karierze zawodowej.

Jednakże, z drugiej strony należy ponownie zaznaczyć, że istnieje pozytywne podejście, także coraz częściej pojawiące się literaturze przedmiotu, do pracy pejoratywnie określanej jako McJob. Jego zwolennicy dostrzegają w zatrudnieniu w barach typu fast food czy też innym sektorze usług możliwości nabycia lub rozwinięcia pewnych umiejętności, które mogą być przydatne ludziom młodym na późniejszych etapach ich drogi zawodowej. Co więcej, postrzegają oni tego typu miejsca pracy jako grunt do awansów zawodowych i rozwoju kariery, którą młodzi mogą rozpocząć jeszcze kształcąc się ze względu na elastyczność czasu pracy ${ }^{41}$, jaka najczęściej występuje na stanowiskach pracy w sektorze usług. Oznacza to, że młodzież ucząca się jest w stanie pogodzić naukę z obowiązkami zawodowymi poprzez dostosowywanie grafiku pracy z zajęciami w szkole czy na uczelni. Ponadto, praca w charakterze McJob może stanowić realny punkt wejścia na rynek pracy przez młodzież poszukującą pierwszego zatrudnienia, zwłaszcza pochodzącą z rodzin imigranckich lub młodych borykających się z innymi problemami, której często nie jest łatwo postawić pierwsze kroki w sferze zawodowej ${ }^{42}$.

Należy jednak wyraźnie zaakcentować, że opisane powyżej pozytywne podejście do McJob nie jest powszechne w społeczeństwie. Jak podkreśla Colin Lindsay oraz Ronald W. McQuaid, eksponujący dobre strony McJob pra-

red. E. Hopper, London 1971, s. 297-298, podaję za: Z. Melosik, Kultura popularna i tożsamość młodzieży, s. 319-320.

${ }^{39}$ Z. Melosik, Uniwersytet i społeczeństwo, s. 135.

40 J.M. Szaban, Rynek pacy w Polsce i Unii Europejskiej, Warszawa 2016, s. 304.

41 A.M. Gould, Working at McDonalds, s. 784-785.

${ }^{42}$ C. Allan, G.J. Bamber, N. Timo, Employment relations in the Australian fast-food industry, [w:] Labour relations in the global fast food industry, red. T. Royle, London 2002, s. 154-74, podaje za: A.M. Gould, Working at McDonalds, s. 784. 
codawcy z sektora usług muszą dążyć do zmiany wizerunku pracy określanej w ten właśnie sposób, która mimo iż charakteryzuje się najczęściej niskim szczeblem zatrudnienia, może oferować realistyczne wynagrodzenie, godne warunki pracy i możliwości osobistego rozwoju ${ }^{43}$. W sposób oczywisty określenie McJob jest kojarzone z restauracjami McDonald's i dlatego pierwsze próby walki z tym terminem podjęła właśnie ta firma, kiedy słowo McJob pojawiło się w słowniku Oxford English Dictionary w roku 1986 i zostało zdefiniowane jako „niezajmująca, nisko płatna praca z niewieloma perspektywami, szczególnie taka, która powstała dzięki rozszerzeniu sektora usług" ${ }^{44}$. Niestety, pomimo starań, do dziś nie udało się przedsiębiorstwu McDonald's wyprowadzić tego słowa ze wspomnianego słownika i obecnie znajduje się także $\mathrm{w}$ jego wersji online, gdzie możemy przeczytać, że oznacza ono „nisko opłacaną pracę z niewieloma perspektywami"45.

Firma McDonald's jest także znana z kampanii marketingowych, między innymi emitowanych $\mathrm{w}$ telewizji, którymi próbuje "ocieplić" swój wizerunek i przedstawić jako dobrego pracodawcę oferującego, wbrew powszechnej opinii na temat McJob, atrakcyjne, ciekawe zatrudnienie dające możliwość rozwoju swoich umiejętności oraz awansu zawodowego. Najnowsza z nich wystartowała w listopadzie 2017 roku pod hasłem „Witamy w McDonald's” i jej głównym celem jest wsparcie wizerunku McDonald's na rynku pracy. Kampania skierowana została do różnych grup potencjalnych kandydatów, w tym osób, które do tej pory nie były w centrum zainteresowania pracodawców z branży gastronomicznej. Poza osobami młodymi, jej przekaz ma trafić więc między innymi do osób z niepełnosprawnościami, pracowników $w$ wieku powyżej 50 lat czy też młodych matek $^{46}$. W tymże spocie reklamowym ukazano pracowników na dwóch płaszczyznach - prywatnej oraz zawodowej, a rolą tego przekazu jest zaprezentowanie firmy jako pracodawcy przyjaznego, a oferowanego przez niego zatrudnienia atrakcyjnego między innymi dla ludzi młodych, aktywnych w wielu sferach życia, dla których praca w McDonald's może stanowić wstęp do kariery zawodowej.

Podsumowując, w moim artykule próbowałam opisać zjawisko makdonaldyzacji pracy, logicznie zajęłam się egzemplifikacją tego zjawiska, jaką jest restauracja McDoanld's. Przedstawione wyżej rozważania prowadzą do sformułowania pewnego wniosku. Podkreślałam w tym tekście, że McDonald's mimo swojej rosnącej popularności ma także negatywny wizerunek w społe-

${ }^{43}$ C. Lindsay, R.W. McQuaid, Avoiding the 'McJobs': unemployed job seekers and attitudes to service work, Work, Employment and Society, 2004, 18(2), s. 297.

${ }^{44}$ C. Allan, G.J. Bamber, N. Timo, Fast-food work: are McJobs satisfying? s. 403.

${ }^{45}$ https://en.oxforddictionaries.com/definition/mcjob, [dostęp 22.03.2018].

${ }^{46}$ McDonald's promuje sie jako pracodawca kampania "Witamy w McDonald's" www.wirtualnemedia.pl/artykul/mcdonald-s-pracodawca-kampania-witamy-w-mcdonald-s [dostęp: 22.03.2018]. 
czeństwie zarówno w kontekście jakości swoich produktów i usług, jak również dehumanizacji wykonywanej w nim pracy. Należy także uwzględnić fakt występującej zmiany dynamiki dyplomu, związanej zarówno ze zróżnicowanymi aspiracjami młodych, jak i zmianami struktury zatrudnienia na rynku pracy. Obecnie, jak wielokrotnie zaznaczałam, występuje nadwyżka absolwentów szkół wyższych na rynku pracy, co powoduje, że część z nich zmuszona jest do podjęcia zatrudnienia poniżej swoich kompetencji i jakości formalnych kredencjałów. Jednakże, należy również zwrócić uwagę, że podobnie jak część pragnących „zrobić” karierę kobiet przesuwa decyzję o posiadaniu dziecka, tak i część młodych ludzi przesuwa decyzję o podjęciu starań o stabilną, linearną pracę. Widzą oni swoją przyszłość często w zmultiplikowanych perspektywach, a stabilna praca niekoniecznie jest dla nich priorytetem. Ponadto, faktem jest, że McDonalds's pozwala na zdobywanie doświadczenia zawodowego przez ludzi młodych dopiero co wkraczających na rynek pracy i z tych wszystkich powodów jednoznaczna negatywna ocena zmakdonaldyzowanej pracy nie jest słuszna. Przedstawione przeze mnie wyżej analizy prowokują do stwierdzenia, iż każde zjawisko społeczne, nawet uważane powszechnie za negatywne, w tym przypadku McJob, warto przeanalizować z odmiennej perspektywy, dzięki czemu paradoksalnie możliwe jest dostrzeżenie pewnych pozytywnych „skutków ubocznych”.

\section{BIBLIOGRAFIA}

Allan C., Bamber G.J., Timo N., Fast-food work: are McJobs satisfying? Employee Relations, 2006, 28(5).

Bauman Z., Consuming life, Journal of Consumer Culture, 2001, 1(1).

Coupland D., Generation X., Tales for an accelerated culture, St Martin's Press, New York 1991.

Debord G. , Społeczeństwo spektaklu oraz rozważania o społeczeństwie, Państwowy Instytut Wydawniczy, Warszawa 2006.

Etzioni A., The fast-food factories. McJobs are bad for kids, https://www.washingtonpost. com/archive/ opinions/1986/08/24/the-fast-food-factories-mcjobs-are-bad-for-kids/b3d7bbeb-5e9a-4335-afdd-2030cb7bc775/?utm_term=.da787f27c4f0 [dostęp: 18.03.2018].

Gould A.M., Working at McDonalds: some redeeming features of McJobs, Work, Employment and Society, 2010, 24(4).

Gromkowska-Melosik A., Edukacja i nierówność społeczna kobiet. Studium dynamiki dostępu, Oficyna Wydawnicza Impuls, Kraków 2011.

http://www.mcdonalds.co.uk/ukhome/whatmakesmcdonalds/questions/work-with-us/jobs/how-many-people-are-employed-by-mcdonalds-in-the-uk-and-worldwide. html [dostęp: 26.03.2018].

https://en.oxforddictionaries.com/definition/mcjob [dostęp: 22.03.2018].

Jasińska-Kania A., Marody M. (red.), Polacy wśród Europejczyków. Wartości społeczeństwa polskiego na tle innych krajów europejskich, Wydawnictwo Naukowe Scholar, Warszawa 2002. 
Kowalewska S., Humanizacja pracy, Wydawnictwo Związkowe CRZZ, Warszawa 1971.

Leidner R., Fast food, fast talk. Service work and the routinization of everyday life, University of California Press, Berkley 1993.

Lindsay C., McQuaid R.W., Avoiding the 'McJobs': unemployed job seekers and attitudes to service work, Work, Employment and Society, 2004, 18(2).

Macionis J.J., Benokraitis N.V., Seeing ourselves. Classic, contemporary, and coss-cultural readings in sociology, Pearson Prentice-Hall, New Jersey 2001.

McDonald's promuje sie jako pracodawca kampania "Witamy w McDonald's" www.wirtualnemedia.pl/artykul/mcdonald-s-pracodawca-kampania-witamy-w-mcdonald-s [dostęp: 22.03.2018].

Melosik Z., Uniwersytet i społeczeństwo. Dyskursy wolności, wiedzy i władzy, Oficyna Wydawnicza Impuls, Kraków 2009.

Melosik Z., Kultura popularna i tożsamość młodzieży. W niewoli władzy i wolności, Oficyna Wydawnicza Impuls, Kraków 2013.

Reich M., Gordon D.M., Edwards R.C., Dual labor markets. A theory of labor market segmentation, American Economic Review, 1973, 63(2).

Ritzer G., Magiczny świat konsumpcji, Warszawskie Wydawnictwo Literackie Muza, Warszawa 2001.

Ritzer G., McJob. McDonalidization and the workplace, [w:] Seeing ourselves. Classic, contemporary, and cross-cultural readings in sociology, red. J.J. Macionis, N.V. Benokraitis, New Jersey 2001.

Ritzer G., Makdonaldyzacja społeczeństwa, Warszawskie Wydawnictwo Literackie Muza, Warszawa 2003.

Sikorska M., Zmiany postaw Polaków wobec pracy, [w:] Polacy wśród Europejczyków. Wartości społeczeństwa polskiego na tle innych krajów europejskich, red. A. Jasińska-Kania, M. Marody, Wydawnictwo Naukowe Scholar, Warszawa 2002.

Smart B., Resisting McDonaldization, Sage, London 1999.

Szaban J.M., Rynek pacy w Polsce i Unii Europejskiej, Wydawnictwo Difin, Warszawa 2016.

Treiber L.A., McJobs and pieces of flair: linking McDonaldization to alienating work, Teaching Sociology, 2013, 41(4). 